\title{
Going somewhere slowly? An assessment of the pace of local government HIV/AIDs multisectoral responses in African cities
}

Commonwealth Journal of Local Governance

Issue 15: June 2014

http://epress.lib.uts.edu.au/ojs/index.php/cjlg

\section{Francis Kintu}

University of the Witwatersrand

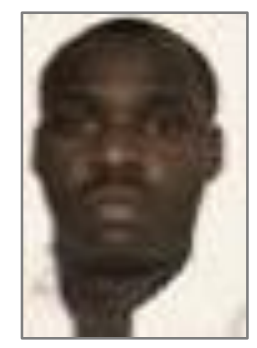

\begin{abstract}
Sub-Saharan African (SSA) countries have the highest rates of HIV prevalence in the world accounting for an estimated $71 \%$ of all new infections (UNAIDS 2010). HIV prevalence is greatest in urban informal areas, caused largely by the proliferation of a variety of risk environments that facilitate the rapid spread of HIV/AIDS. As a strategic response to the complex nature of the HIV/AIDs epidemic in urban areas, decentralised multisectoral HIV/AIDs responses at the local government level have been adopted. These are seen as a sustainable way of dealing with the spread of HIV/AIDs in a number of African cities, in line with internationally accepted recommendations. Now that a number of local governments in African cities have adopted HIV/AIDS multisectoral responses, the question can be asked to what degree is this is this response being implemented in these countries, and what challenges are faced by cities as they adopt this approach? This article reviews HIV/AIDS multisectoral responses in African cities, and discusses the challenges that face urban local governments as they implement these responses.
\end{abstract}




\section{The urban context of HIV/AIDS in Africa}

Surges in the levels of urbanisation in African countries are increasing unabated; with statistical projections that estimate that by 2030 well over $50 \%$ of the African population will be living in cities (UN 2009). The rapid increase in urban migration to cities in Africa has resulted in the proliferation of informal settlements. These cities have the highest proportion of urban dwellers relative to overall population in the world (Napier 2007).

It is estimated that seven out of ten residents in sub-Saharan African cities live in informal settlements. These are often located in outlying or peripheral areas; in places that are not wholly suited for human habitation (UN Habitat 2003). The high concentrations of people in urban informal areas, and the attendant consequences of ill health, overcrowding, the lack of adequate shelter and the lack of water and sanitation, has urbanised poverty (UN Habitat 2003). A key feature of this phenomenon is the burgeoning of the serious health risk environments in urban informal settlements (UN Habitat 2010; Van Donk 2006).

In terms of the social determinants of health framework, the status of peoples' health is largely determined by their socio-economic environment (Dahlgren \& Whitehead 1991; Wilkinson \& Marmot 2008). Urban informal settlements, as 'spaces of health inequality', are environments that pose serious health risks as they incubate HIV/AIDS, tuberculosis (TB) and other diseases (Hunter 2006). In addition, rapid urbanisation in African countries has been accompanied by the resurgence of 'old' epidemics such as cholera, dysentery, typhoid fever (David et al. 2007).

Factors that accompany the 'urbanisation of poverty', such as the lack of access to proper housing and health care, malnutrition, the lack of adequate water and sanitation, all tend to accelerate the spread of HIV/AIDs as they create greater vulnerability to infection. Malnutrition impairs the immune system and lowers resistance to infection, while overcrowding in housing settlements accelerates the spread of HIV/AIDs. The capacity of informal settlements to cope with infections is greatly reduced due to barriers of access to preventive, diagnostic and curative health services.

As a result, levels of HIV/AIDs prevalence in cities are much higher than those of rural areas (Van Donk 2006). Furthermore, its prevalence in urban informal areas is significantly higher than that of urban formal areas and rural areas. For example in Uganda, the Democratic Republic of Congo (DRC), Kenya, Rwanda, Tanzania and South Africa, HIV/AIDs prevalence in urban informal areas has been reported to be 2 to 5 times higher than that of rural areas (USAID 2002). In Johannesburg, its prevalence in adults aged 15 to 49 years by locality type is almost twice in urban informal areas $(17.3 \%)$ than that of urban formal areas (9.7\%) (Tomlinson 2006). 


\section{Local governments and multisectoral efforts in African urban areas}

International efforts to control the rapid spread of HIV/AIDs have recognised the need to address the multiplicity of factors which contribute to the depth of its impact on communities, as well as the need to target the 'social ecology' (the factors in the environment that drive) of infections (Decosas 2002; Van Donk 2006). Multisectoral responses to HIV/AIDs consisting chiefly of development-based strategies working in tandem with health care preventive and curative services have risen to prominence as sustainable ways to deal with the epidemic (Elsey \& Kutengule 2003; UNAIDS 2013).

It is argued that decentralised multisectoral efforts hold the key to containing the spread of HIV/AIDs in urban areas in Africa, as opposed to standalone health based responses (UNDP 2006). Several international agencies such as the World Bank, UNAIDS and UN HABITAT have taken the lead in implementing decentralised multisectoral responses in African cities in recognition of the important role that they play in curbing the spread of HIV/AIDs (UNAIDS 2003).

For example, UN-Habitat as the United Nations lead agency for shelter and local authorities advocates for the implementation of decentralised multisectoral responses in urban areas based on the premise that local government, as an institution that is nearest to communities, is strategically placed to deal with the multifaceted nature of HIV/AIDs (UN Habitat 2003). Since the mid-1990s to the present, HIV/AIDs strategies in African countries have evolved from centralised, health sector responses to multisectoral efforts coordinated by a National AIDS Council or Commission, with the greater responsibility of implementation being devolved to individual sectors and decentralised to sub-national levels (Elsey \& Kutengule 2003; UNAIDS \& GTZ 2002; UNAIDS 2013; UNDP 2006; World Bank 1999).

Decentralised, sub-national multisectoral efforts in African countries typically involve the devolution of the implementation of national HIV/AIDs strategies to the local level. This involves the vertical coordination among national, district and local levels, in terms of how these tiers of government cooperate to ensure the implementation of the country's National AIDS Strategic Framework (UNDP 2005; UNDP 2006). Decentralised efforts also involve cross-sectoral collaboration at the local level, between local government and various civil society actors such as community based organisations (CBOs), non-governmental organisations (NGOs) and trade unions. Local government, as the sphere nearest to communities, takes on a central role in implementing nationally mandated HIV/AIDS strategies. This is done by translating national plans into community responses through the promotion of cross-sectoral processes that involve civil society, government departments, as well as other stakeholders in formulating effective HIV/AIDS multisectoral activities. 
The translation of national HIV/AIDS strategies into viable multisectoral responses requires efficient local governance processes that ensure the increased participation of civil society, nongovernmental actors and vulnerable groups in local HIV/AIDS activities (Center for Municipal Research \& Advice 2009). Effective local governance processes consisting of horizontal coordination processes at the local level, as well as vertical integration processes between tiers of government ensure that national goals and aims are articulated into meaningful decentralised multisectoral responses.

The formulation of decentralised approaches in communities is reliant on the integration of HIV/AIDs in local government activities. This involves its inclusion in organisational (internal mainstreaming) and sectoral planning. Effective local governance ensures the integration of HIV/AIDS in planning in order to mitigate its impacts in communities as well as to address factors that 'drive' susceptibility to HIV/AIDs (DPLG 2007; Elsey \& Kutengule 2003; UNAIDS 2003; Van Donk \& Stacy-Leigh 2008). The figure below shows local government processes in implementing decentralised multisectoral responses to HIV/AIDS:

Figure 1: Local government processes in implementing HIV/AIDs decentralised multisectoral responses

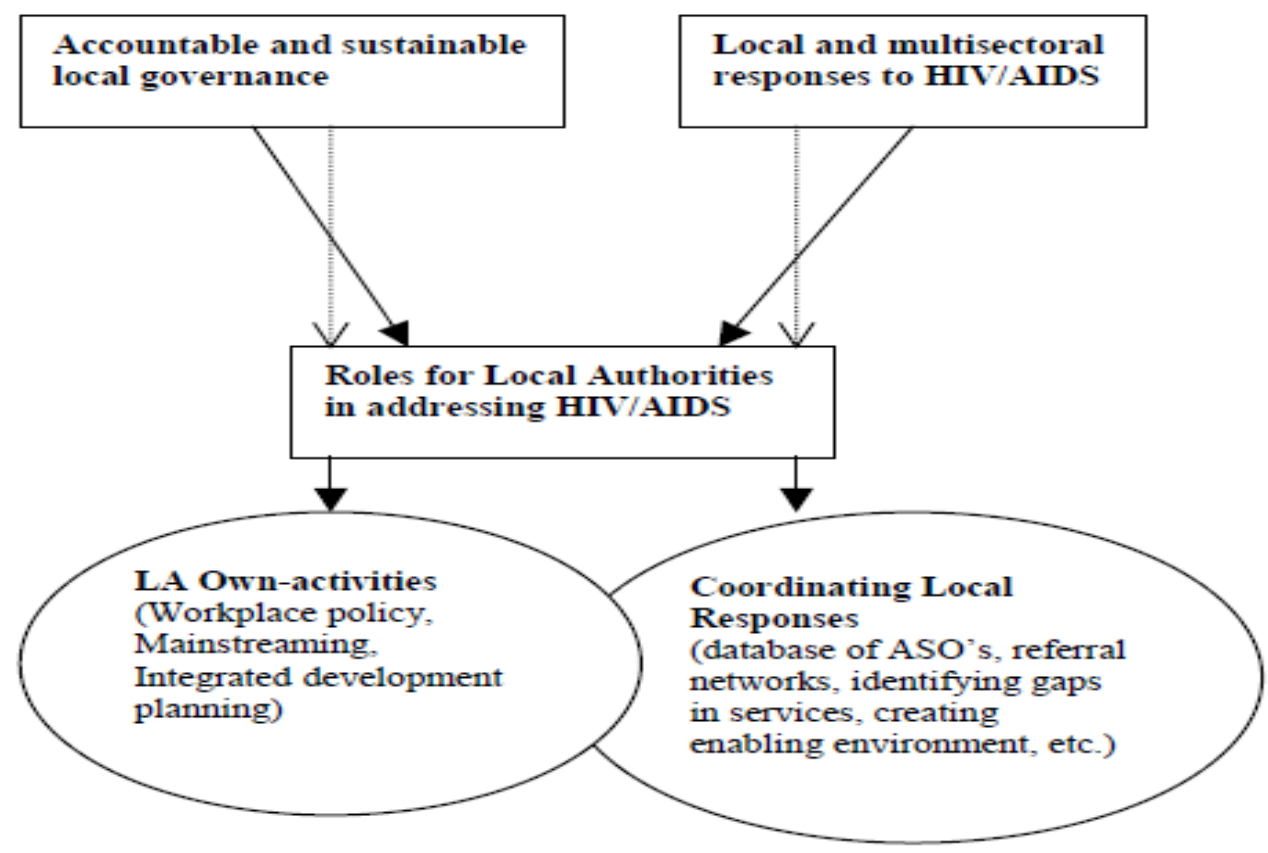

Source: Schuler 2004 
A typical example of a decentralised multisectoral response to HIV/AIDs is South Africa's Framework for an Integrated Local Government Response, formulated by the Department of Provincial and Local Government ${ }^{1}$ in 2007. Conceived as a development and governance approach, the framework emphasises the active role of local government in implementing development based responses to the impact of HIV/AIDs in communities as a sustainable and adequate response to the pandemic (DPLG 2007; SALGA 2008).

The Framework for an Integrated Local Government Response recognises the central role that local government plays in implementing development and governance responses to HIV/AIDs. It recommends the mainstreaming of HIV/AIDS into community planning processes by using integrated development plans ${ }^{2}$ (IDPs), to address issues of vulnerability to infection and susceptibility to the impacts of HIV/AIDS (DPLG 2007; SALGA 2008).

Using IDPs as mechanisms to mainstream HIV/AIDs is highly strategic. Planning targets the diverse socio-economic factors that have a direct bearing on the deprivation of households affected and infected by HIV/AIDS, as well as the conditions that encourage the spread of infection in communities (DPLG 2007; SALGA 2008). IDPs can drive strategic interventions such as the provision of effective food-security safety nets, the delivery of efficient and spatially accessible social services and the establishment of flexible cost-recovery mechanisms that take into account household income and expenditure levels in order to alleviate the burden of suffering and deprivation experienced by households affected by HIV/AIDs (DPLG 2007).

In line with international guidelines, the Framework for an Integrated Local Government Response supports the mainstreaming of HIV/AIDS within the core business of development planning practices of local government. This means that every line department within municipalities adapts its core work to take into account susceptibility to HIV infection and vulnerability to the impacts of AIDs among communities within the municipal area. This also means identifying the existing possibilities and opportunities for reducing susceptibility and vulnerability to HIV/AIDS in communities (DPLG 2007; SALGA 2008).

Interestingly, the framework views the roles of local government in implementing HIV/AIDS multisectoral responses as that of a doer, an enabler/regulator, a co-ordinator/facilitator and a connector (DPLG 2007). As a doer, local government authorities take direct responsibility for implementing nationally mandated strategic responses to HIV/AIDs, by translating them into local responses aligned with its institutional and financial capacity.

\footnotetext{
${ }^{1}$ Now known as the Department of Cooperative Governance and Traditional Affairs (CoGTA).

2 Integrated development plans are comprehensive strategic and corporate planning instruments formulated by municipalities in South Africa for executing socio-economic development in communities. They are one of the core elements of a municipality's responsibilities as legislated in the Municipal Systems Act, 2000.
} 
As an enabler or regulator, the municipality creates a conducive space that allows the participation of all stakeholders in the local response to HIV/AIDS as part of its regulatory and other functions. As a coordinator or facilitator, local government authorities by dint of horizontal and vertical integration coordinate a whole range of responses undertaken by other stakeholders, such as provincial and national government departments, NGOs, CBOs, traditional authorities and the private sector. As connector, the municipality links demand-side stakeholders to service providers, or facilitates linkages between suppliers of service provision and care with communities where the demand of services is needed.

A good example of the implementation of decentralised HIV/AIDs responses is found in Malawi, where the GIZ-Malawi Government Program on Democracy and Decentralisation (MGPDD), actively supports the district councils of Chitipa, Karonga, Mzuzu City; Nkhotakota, Salima, Kasungu Municipality; Ntchisi, Balaka, Zomba City and Luchenza Municipality in formulating local level responses to HIV and AIDS (all Africa 2013).

These district and city councils support the fight against HIV/AIDS by developing local, harmonized implementation plans in line with the Malawi HIV and AIDS Extended National Action Framework 2010-2012. District and city plans are evidence-based so that the interventions address real issues that contribute to the spread of HIV/AIDs. District AIDS Coordination Committees play a valuable role in directing and coordinating issues of policy guidance to districtlevel HIV/AIDS responses in accordance to the stipulations of the extended National Action Framework or NAF (all Africa 2013).

All district and city councils located within the Ministry of Local Government and Rural Development (MoLGRD), are responsible for coordinating and implementing HIV/AIDS strategies through the District AIDS Coordination Committees (DACC) (all Africa 2013). At the national level, the Malawi National AIDS Commission (NAC), working with the Department of Nutrition, HIV \& AIDs (DNHA) coordinates activities in accordance with the National HIV/AIDS Strategic Framework as directed in the programs of various stakeholders involved in the fight against the disease, such as CBOs, trade unions and traditional healers among others. 
One of the hallmarks of the formulation of the decentralised response in Malawi is the Blantyre City Assembly HIV/AIDS Initiative ${ }^{3}$. Under this initiative, local government collaborates with various sectors and groups such as government departments, CBOs, as well as NGOs among others in coordinating city-wide HIV/AIDs projects. In this way, thousands of Blantyre residents have been involved through a variety of outreach and community programs supported by the Blantyre City Assembly (UN Habitat 2006). Over 15 voluntary counselling and testing (VCT) centres have been established, and an HIV/AIDS resource centre exists in the City Assembly (UN Habitat 2006).

Elsewhere, bold steps have been taken in implementing decentralised local government responses to HIV/AIDs. The Alliance of Mayors Initiative for Community Action on AIDS at the Local Level (AMICAALL) is an African HIV/AIDs multisectoral initiative that was launched in 1998. AMICAALL promotes a partnership approach to implementing local government HIV/AIDS responses by encouraging cooperation and coordination between the local government and civil society. Collaboration is central to the organisation of AMICAALL, which is built upon networks within and across countries. AMICAALL recognises that while empowering local government leaders to address HIV/AIDS is critical, to be effective any response to HIV/AIDS must be integrated with ongoing activities at the local and national levels (AMICAALL 2013).

Currently, there are AMICAALL National Chapters operating in more than 13 African countries including Uganda, Namibia, Swaziland, Côte d'Ivoire, Burkina Faso, Mali, Tanzania, South Africa, Zambia, Malawi, Central African Republic, Kenya and Cameroon. AMICAALL's mission statement - 'to develop and coordinate the political and technical capacity of local government in Africa to effectively lead the multisectoral response to HIV and AIDS at the local level, in accordance with the principles of the Abidjan Declaration' echoes its resolve to support urban led, multisectoral responses (AMICAALL 2010).

AMICAALL's strategy operates on several fronts. Firstly, it is inclusive in that it involves a broad range of stakeholders. Secondly, it is responsive. It reacts to locally articulated needs by encouraging dialogue among local people, municipalities, policy-makers and decision-makers in the implementation of HIV/AIDs responses. Thirdly, it is gender sensitive with respect to responding to the different experiences of men and women in terms of vulnerability, response and impact. Lastly, it is dynamic. Local action informs national policy which in turn contributes to a more enabling environment for sustained responses. Strengthened management and financial systems at the local level provide the foundations for scaling up responses to the epidemic (AMICAALL 2010).

\footnotetext{
${ }^{3}$ The Blantyre City Assembly HIV/AIDS Initiative is listed among the World Banks's internationally recognised best practices of HIV/AIDS mainstreaming processes.
} 
The actions of AMICAALL and its chapter members operating in different countries are concrete examples of how local governments in African cities working in partnership with civil society and local communities are able to translate the goals of National AIDS Strategic Plans or Frameworks into concrete action. The AMICAALL Kenya program works in close collaboration with the Kenya National AIDS Control Commission and other partners in the country to promote a coordinated, multi-sectoral response to HIV/AIDS in cities and towns in Kenya. Since its launch in 2004, AMICAALL Kenya has facilitated the establishment of 135 Municipal AMICAALL Committees, each with its own structure and budget lines for local HIV/AIDS responses. Programs being implemented by these Municipal Committees include: raising the awareness of local authority leadership to HIV/AIDs issues; advocacy and lobbying of key decision makers on the importance of local HIV/AIDS responses, and networking and support to preparation of workplace policies, municipal profiles and service directories (AMICAALL Kenya 2013).

The AMICAALL Kenya program has provided valuable support to local government. For example, it has helped the local government in Kisumu to develop a municipal HIV response program as well as in Nairobi where it helped the City Council launch its HIV workplace program (AMICAALL Kenya 2005). Through activities such as these, AMICAALL Kenya supports local government to identify priority actions that can be undertaken at the ward and local government levels to expand much needed services and support to vulnerable households and communities complementing national efforts (AMICAALL Kenya 2005).

Other African cities where AMICAALL initiatives continue to play a key role are Kampala, (Uganda), Blantyre (Malawi), Makurdi (Nigeria), Ndola (Zambia), Abengourou (Ivory Coast) and Johannesburg and Msunduzi (South Africa). These AMICAALL initiatives are assisted by UNHABITAT (AMICAALL 2010). 


\section{Executing HIV/AIDS multisectoral responses in African cities.}

Notable HIV/AIDs multisectoral success stories in African cities have been documented in research reports and in literature that documents the status of mainstreaming HIV/AIDs in Africa. In the metropolitan city of Msunduzi ${ }^{4}$ in South Africa for example, the adoption of the HIV/AIDS Ward Strategy in 2004 as an innovative, comprehensive, award winning ${ }^{5}$ municipal response to the disease throughout the city deserves mention as an effective way of driving multisectoral responses in urban communities.

The strength of the Msunduzi HIV/AIDS Ward Strategy is predicated on the key parts of the South African National HIV/AIDS and STI Strategic Plan (2007-2011) that emphasise prevention, health care and support for infected and affected households. The Ward Strategy is underpinned by robust partnerships forged between local government, several civil society groups and other partners in the city to implement municipal multisectoral responses (Built Environment Support Group 2007a; Built Environment Support Group 2007b). The advantage of the strategy lies in its cross-sectoral scope where the Msunduzi local government works with various civil society groups, other government departments, NGOs, private and business sectors in supportive relationships that promote opportunities for constructive engagements that help optimise and expand HIV/AIDs service provision to all communities ${ }^{6}$ (Built Environment Support Group 2007a).

The Ward Strategy owes its success to political and administrative championing at the highest level of local government, as well as to internal and external capacity strengthening that has built a committed cadre of staff and volunteers ${ }^{7}$ who are actively engaged in HIV/AIDs mainstreaming activities (Built Environment Support Group 2007a). Key achievements of the strategy, among others, such as the expansion of VCT provision in all communities, the involvement of over 60 CSOs in HIV/AIDS projects, the establishment of a Msunduzi Referral Network ${ }^{8}$ that links CSOs, municipal and provincial clinics and the initiation of interventions in housing to cater for the mitigation of HIV/AIDS impacts in communities are attributed to the presence of effective local governance co-ordination systems (Built Environment Support Group 2007a).

What the internationally acclaimed Msunduzi Ward Strategy illustrates is the necessity of highly effective partnerships between municipalities and CBOs in driving city wide multisectoral responses, and the development of ward-level co-ordination and funding forums that link communities. The strategy also illustrates the role played by committed political leadership in driving local HIV/AIDS responses, as well as the strength of the cross-sectoral focus of the HIV/AIDs response that is built on the strength of community mobilisation and capacity building efforts (Built Environment Support Group 2007a).

\footnotetext{
${ }^{4}$ Formerly known as Pietermaritzburg. Msunduzi City is also the capital city of the province of Kwa Zulu Natal.

${ }^{5}$ The Msunduzi Ward Strategy won the coveted 2004 Dubai International Award for Best Practices (DIABP).

${ }^{6}$ By 2007, the strategy had already been rolled out to 30 out of 37 wards in the communities of Msunduzi.

${ }^{7}$ There are approximately 600 volunteers who provide care and support to the communities.

${ }^{8}$ Also known as the Msunduzi HIV/AIDS Network.
} 
Despite successes in effecting HIV/AIDs municipal responses in other African cities, such as the DISC $^{9}$ programme in Dakar (Senegal), the Ndola City HIV/AIDs programme (Zambia), the PLACE $^{10}$ HIV/AIDs intervention programme in Burkina Faso and the Eritrea Rapid Results approach (World Bank 2006), there are a quite a number of daunting obstacles that need to be overcome in order to realise sustainable HIV/AIDs multisectoral responses in African cities. Admittedly, mainstreaming HIV/AIDs is a recent phenomenon that is still evolving in practice. In this respect, integrating processes at sub-national levels poses formidable challenges of coordination that are related to the complexities of decentralisation (Schuler 2004; South African Cities Network 2004; UNAIDS 2003; Van Donk \& Stacy-Leigh 2008).

Evidence in literature strongly suggests that HIV/AIDs multisectoral responses are significantly hampered by weaknesses in decentralised local governance processes with respect to issues related to the coordination of strategies between sectors and between levels of government (Boex \& Yilmaz 2010; Kelly 2004; Schuler 2004; South African Cities Network 2004; Van Donk \& StacyLeigh 2008; Tomlinson 2006; UNAIDS 2003; UNDP 2005; UNDP 2006).

Common problems associated with coordination issues that obstruct the effective execution of mainstreamed responses are the lack of clarity about the powers and functions of different tiers and spheres of government, poor integration of vertically decentralised departments (particularly health departments) at the local level, the lack of support for intergovernmental relations and cocoordinating structures, and poorly articulated frameworks for fiscal decentralisation and unfunded mandates for local government to respond to HIV/AIDS (Boex \& Yilmaz 2010; Kelly 2004; Siddle \& Koelble 2012; UNAIDS 2003).

Serious problems of horizontal coordination between local government and diverse stakeholders are cited in literature, pointing to the frailty of cross-sectoral, collaborative planning processes at the local level of government (DPLG 2006; Kelly 2004; Mahlangu et al. 2010; UNDP 2006; Van Donk \& Stacy-Leigh 2008). Weaknesses in collaboration between local government and local stakeholders as manifest in the significant lack of vibrant, cohesive working partnerships between government departments and civil society groups and the private sector, is a strong indicator of weak local governance (Schuler 2004; South African Cities Network 2004).

Other challenges involve the lack of capacity in terms of planning and managing the affairs of local government beyond the delivery of basic services, especially with regard to managing the new demands of planning for HIV/AIDS. Several urban municipalities in Gauteng province in South Africa, for example, are still struggling to implement multisectoral HIV/AIDs strategies in communities because of problems related to lack of capacity and skills (South African Cities Network 2004; Siddle \& Koelble 2012).

\footnotetext{
${ }^{9}$ DISC (Décentralisation et Initiatives de Santé Communautaire) is a small community health organisation in Dakar, Senegal that works towards developing the capacity of district LGAs for responding to health needs.

${ }^{10}$ PLACE - Priorities for Local AIDS Control Efforts is a methodology that is used to gather local information by mapping high transmission areas or 'Zones d'Interventions Prioritaires' at the district level in two districts (Tenkodogo, Banfora).
} 


\section{Conclusion}

It is patently clear that problems related to decentralisation dominate with regard to the challenges faced by local governments in executing multisectoral HIV/AIDs responses in African cities. This has been largely attributed to weaknesses present in decentralisation processes which are a common feature in many African countries (Boex \& Yilmaz 2010; Kelly 2004; Schuler 2004; Siddle \& Koelble 2012).

There is a direct correlation between the strength of decentralisation processes at subnational levels and the state of local HIV/AIDs mainstreaming processes (Built Environment Support Group 2007; Schuler 2004; South African Cities Network 2004; Van Donk \& Stacy-Leigh 2008). The potency of HIV/AIDs multisectoral responses rests squarely on the shoulders of successful decentralisation processes that are at the heart of local governance processes that support the implementation of effective municipal HIV/AIDs responses in African cities.

Weak decentralisation at subnational levels does in fact hamper the operation of local governance processes that support the successful implementation of multisectoral responses in African cities. Unsuccessful decentralisation is a major threat to socio-economic stability in African countries and disrupts the provision of public service delivery processes with a telling impact on HIV/AIDs mainstreaming processes (South African Cities Network 2004; Schuler 2004; Tomlinson 2006; World Bank 1999).

For viable multisectoral responses to thrive, it is incumbent upon African countries to initiate programs of decentralisation reform that can bolster the effective functioning of local government and its attendant activities. Key parts of these decentralisation reform processes must seek to address the status of intergovernmental planning in ways that can support the articulation of national HIV/AIDS strategies in urban communities (Schuler 2004).

Lastly, local government reform programs must also strengthen the operation of sustainable and vibrant partnerships in which local government interacts successfully with stakeholders who have a vital part to play in HIV/AIDS mainstreaming for urban communities such as such as government departments, NGOs, business sector organisations, trade unions and civil society groups among others. The continued existence of these partnerships holds the key to the formulation of local HIV/AIDs responses with respect to how well households in urban communities are provided with coping strategies that shield them from exposure to the baleful impact of the disease as well as providing them with optimal levels of socio-economic safety to decrease their susceptibility to infection. 


\section{References}

All Africa 2013. Karonga Struggles With 17 Percent HIV/Aids 17 Prevalence Rate. www. allafrica.com/stories/201307261160.html

AMICAALL. 2010. Alliance of Mayors and Municipal Leaders on HIV/AIDS in Africa 2009 - 2014 Strategic Plan. http://www.amicaall.org/2009-2014 Strategic Plan

AMICAALL Kenya. 2005. Alliance of Mayors and Municipal Leaders on HIV/AIDS in Kenya. Working together at the Local Level. A case study produced by the UN AMICAALL Partnership Programme www.amicaall.org/ken/publications/ICASA_CaseStudyKenyaFinal,2005.pdf

Built Environment Support Group. 2007a. The Msunduzi HIV/AIDS Ward Strategy. A Case Study of a Partnership Response to HIV/AIDS at Local Government Level. GGLN Learning Event on HIV/AIDS,

Local Government and Human Settlements Planning. www.besg.co.za/downloads/Msunduzi_HIVAIDS_Strategy_2003.pdf

Built Environment Support Group. 2007b. Mainstreaming HIV/AIDS through community participation structures and mobilization of ward committees. Draft input paper prepared by BESG for HALOGEN Learning Event. www.halogen.org.za/.../Input\%20Paper_Community_Participation_and_HIV_AIDS.pdf

Boex, J, \& Yilmaz S.2010. An Analytical Framework for Assessing Decentralised Local Governance and the Local Public Sector. Urban Institute Centre on International Development and Governance. IDG Working Paper No. 2010-06

Centre for Municipal Research and Advice. 2009. Benchmarking HIV/AIDS Newsletter. Issue 2.

Dahlgren G,. \& Whitehead M. 1991. Policies and Strategies to Promote Equity in Health. Stockholm: Institute for Future Studies.

David, A., Mercado, S., Becker, D., Edmundo, K \& Mugisha, F. 2007. The Prevention and Control of HIV/AIDS, TB and Vector-borne Diseases in Informal Settlements: Challenges, Opportunities and Insights. Journal of Urban Health, 84(1), p 2.

Decosas, J. 2002. The Social Ecology of AIDS in Africa. Draft paper prepared for the UNRISD project of HIV/AIDS and Development.

Department of Provincial and Local Government. 2007. Framework for an Integrated Local Government Response to HIV/AIDS.

The Department of Provincial and Local Government, Republic of South Africa. www.gov.za/documents/download.php?f=107412

Elsey, H., and Kutengule, P, 2003. HIV/AIDS Mainstreaming: A Definition, Some Experiences and Strategies, Durban, Health Economics and HIV/AIDS Research Division (HEARD), University of Kwa Zulu Natal \& Accra, Department for International Development, Ghana Office.

Hunter, M. 2006. Center for Civil Society Report no 44. Dartmouth College.

Kelly, K. 2004. Supporting local government responses to HIV/AIDS: Positions, Priorities, and Possibilities. Centre for AIDS Development Research \& Evaluation (CADRE). http://www.cadre.org

Mahlangu, P., Thomas, L., and Vearey, J. 2010.Challenges in mainstreaming HIV and AIDS in local government: A case study of ten urban municipalities in South Africa. Wits School of Public Health. http://www.hivaids-uwc.org.za/docs/Pinky_Mahlangu.pdf

Napier, M. 2007. Informal settlement integration, the environment and sustainable livelihoods in subSaharan Africa. Council for Scientific \& Industrial Research in South Africa (CSIR).

Schuler, N. 2004. Case Study on Local Government Responses to HIV/AIDS in Kenya. World Bank. Transport and Urban Development Department. http://info.worldbank.org/etools/docs/library134438

Siddle, A., and Koelble, T.A. (2012). The failure of decentralisation in South African Local Government: complexity and unanticipated consequences. Claremont, UCT Press.

South African Cities Network, 2004.South African cities \& HIV/AIDS: Challenges and responses. www.cadre.org.za/files/governancecitiesandhiv.pdf 
South Africa Local Government Association. 2008.Country Guideline on HIV and AIDs for Local Government. http:// www.salga.org.za/pages/Municipal-Guidelines-on-HIV-and-AIDS

Tomlinson, R. 2006. Impacts of HIV/AIDS at the Local Level. Report prepared for UN HABITAT. http://web.wits.ac.za/NR/rdonlryes/Cities_in_a_world_of_cities.ppt

UNAIDS 2010. Outlook Report, 2010. http://www.unaids.org

UNAIDS/GTZ. 2002. Mainstreaming HIV/AIDS, a conceptual framework and implementing principles, JSA Consultants Ltd \& GTZ Regional AIDS Programme Accra, Ghana.

UNDP 2005. Mainstreaming HIV/AIDS in sectors and programmes: an implementation guide for National Responses http://www.undp.org/content/dam/aplaws/publication/en/publications/hivaids/mainstreaming-hiv-and-aids-in-sectors-and-programmes--guide/19.pdf

UNDP 2006. Evaluation of UNDP's role and contributions in the HIV/AIDs response in Southern Africa and Ethiopia. Evaluation Office. www.undp.org/eo/documents/EO_HIVAIDSbrief_1.pdf

UN Habitat 2002. The management of the HIV/AIDS pandemic at the local level. UN Habitat World Urban Forum. http://www.unhabitat.org

UN Habitat 2003. Foreword. The Challenge of Slums. Global report on Human Settlements. www.aq.upm.es/habitabilidadbasica/docs/recursos/monografias/the_challenge_of_slums-(2003).pdf

UN Habitat 2006. Managing HIV/AIDS at the local level in Africa. Summaries of city level achievements. http://www.unhabitat.org

UN Habitat 2010. Hidden Cities: unmasking and overcoming health inequities in urban settings. www.unhabitat.org/pmss/listItemDetails.aspx?publicationID=3049

UN 2009. World Urbanisation Prospects Report. 2009. Department of Economic and Social Affairs Population Division. www.esa.un.org/unpd/wup/Documents/WUP2009Highlights Final.pdf

USAID 2002. HIV/AIDS Health Profile: Sub-Saharan Africa. www.pdf.usaid.gov/pdfdocs/pdacu659.pdf

UNAIDS 2003. Mainstreaming HIV/AIDs in Sectors and Programmes. http://www.unaids.org

UNAIDS \& GTZ. 2002. Mainstreaming HIV/AIDS: A conceptual framework and implementing principles. www.afronets.org/files/mainstream.pdf

UNAIDS 2013. Aids response in the Post-2015 Development Agenda. www.unaids.org/.../unaids/.../agendaitems/20131113_AIDS\%20update\%

Van Donk, M. 2006. Positive urban futures in sub-Saharan South Africa: HIV/AIDs and the need for ABC (A Broader Conceptualisation). Environment and Urbanisation. Vol 18, No 1.April 2006. p155-175.

Van Donk, M., and Stacey-Leigh, J. 2008. The Challenges and Dilemmas of Intergovernmental and Intersectoral Coordination. Input.Ppaper prepared for the Learning Event of the HIV/AIDS and Local Government Learning Network. www.halogen.org.za/documents/Input Paper Challenges of IGR.pdf

Wilkinson, R., and Marmot, M. 2008. Social determinants of health: the solid facts. World Health Organisation Publications. www.euro.who.int/ data/assets/pdf_file/0005/98438/e81384.pdf

World Bank. 1999. Decentralisation: Rethinking Government. World Development Report, 1999-2000: http://dx.doi.org/10.1596/0195211243_Chapter5

World Bank. 2001. Urban development. Local Government responses to HIV/AIDS. Best practices and case studies. http://www.worldbank.org 